\title{
Venous ulcer healing: effect of socioeconomic factors in London
}

Peter J Franks, Nick Bosanquet, Majorie Connolly, Margaret I Oldroyd, Christine J Moffatt, Roger M Greenhalgh, Charles N McCollum

\begin{abstract}
Objective - To determine which social and clinical factors are associated with healing in patients with venous ulceration.

Design - Patients were questioned about social factors at their first visit to a community ulcer clinic. They were treated by high compression bandage system and were interviewed again after 12 weeks. Setting - Community leg ulcer clinics held in health centres throughout Riverside Health Authority in London.

Patients - All patients referred to five community leg ulcer clinics with venous ulceration over a six month period.

Main outcome measures - These were factors significantly associated with healing within 12 weeks of beginning treatment, measured by odds ratio (OR) given by logistic regression analysis.
\end{abstract}

Main results - Of 168 patients with venous ulceration, 87 (52\%) healed after 12 weeks of treatment. Univariate analysis showed that low social class $(O R=3.44,95 \% C I$ $1 \cdot 17,10 \cdot 14)$, lack of central heating $(O R=$ $2 \cdot 22,95 \%$ CI $1 \cdot 18,4 \cdot 18)$, and being single $(\mathrm{OR}=2 \cdot 77,95 \%$ CI $1 \cdot 15,6 \cdot 69)$ were all significantly associated with delayed healing. After adjustment for the known risk factors of ulcer size, ulcer duration, and general mobility only lack of central heating was still significant $(O R=2 \cdot 27,95 \%$ CI $1 \cdot 11$, 4.55). The remaining factors failing to achieve statistical significance because of their inter-relationship with the known risk factors.

Conclusions - Clinical features of the ulcer seem to determine the progress of healing in patients with leg ulceration. Although there were associations between socio-economic factors and poor healing, adjustment for clinical risk factors generally led to lower non-significant associations. Only lack of central heating retained its association and may play a part in prolonging healing of venous ulceration.

(f Epidemiol Community Health 1995;49:385-388)

Leg ulceration is a common source of morbidity in the elderly. Studies have indicated an estimated population prevalence in the UK of $0 \cdot 15$ and $0 \cdot 18 \% .{ }^{12}$ The problem is both age and sex specific with the highest prevalence in women aged over 80 years. In the UK alone, between 70 and 90000 patients suffer from leg ulceration at any one time, and three to four times this number have healed ulcers at risk of recurrence. ${ }^{3}$

Treatment of leg ulceration is generally considered a low priority for the medical profession. Delivery is mainly through community care, particularly by district nurses who treat more than $50 \%$ of patients in their homes. It has been estimated that between $25 \%$ and $50 \%$ of all district nurse time is spent on leg ulcer care, with a high resulting cost, and that patient outcome is poor. ${ }^{4}$

Recent innovations in leg ulcer treatment include the four layer bandage technique (4LB), which provides sustained compression between bandage changes of up to one week. ${ }^{5}$ Adoption of this technique in community leg ulcer clinics throughout the Riverside community Healthcare Trust improved ulcer healing rates from $22 \%$ over 12 weeks in a control audit of current practice to $69 \%$ after 12 weeks following implementation. ${ }^{6}$ This standardised approach to treatment has allowed for a comprehensive investigation of factors that may be important in ulcer healing. This paper represents an investigation into social factors which may influence the outcomes of treatment using the $4 \mathrm{LB}$ and the Riverside system of care.

\section{Patients and methods}

The study group comprised all patients who presented to five of six community leg ulcer clinics in Riverside Health District in London in the first six months after the clinics started. At presentation to the clinics the patient underwent a series of tests to determine their suitability for the 4LB. Essential to this process was the determination of the presence of peripheral arterial leg disease which contraindicates the use of high compression bandaging. ${ }^{6}$ Only patients with an ankle brachial pressure index (ABPI) greater than 0.8 were considered to have sufficient arterial inflow to have this treatment.

At presentation, patients had a clinical assessment of their needs undertaken by specialist nurses followed by a questionnaire administered by a trained interviewer. This addressed several areas of the patients' medical and social history and had been adapted from one previously used in an investigation of venous disease. ${ }^{7}$ The social factors which were investigated were:

- Demographic factors - particularly age, sex marital status, employment and source of income. This included questions on the patients' current work status and types of social benefit which they drew; 
Table 1 Recognised risk factors for venous ulcer healing, given by odds ratios (OR) and $95 \%$ confidence intervals (95\% CI) obtained by logistic regression analysis

\begin{tabular}{|c|c|c|c|c|c|}
\hline & \multicolumn{2}{|c|}{ Healed } & \multicolumn{2}{|c|}{ Unhealed } & \multirow[t]{2}{*}{ OR $(95 \% C I)$} \\
\hline & No & $(\%)$ & No & $(\%)$ & \\
\hline \multicolumn{6}{|l|}{ Ulcer size: } \\
\hline $\begin{array}{l}<10 \mathrm{~cm}^{2} \\
>10 \mathrm{~cm}^{2}\end{array}$ & $\begin{array}{r}82 \\
5\end{array}$ & $\begin{array}{r}(94) \\
(6)\end{array}$ & $\begin{array}{l}58 \\
23\end{array}$ & $(72)$ & $\begin{array}{l}1.00 \\
6.50(2.29,18.49)\end{array}$ \\
\hline \multicolumn{6}{|l|}{ Ulcer duration (mth): } \\
\hline$<1$ & 31 & (36) & 14 & (17) & 1.00 \\
\hline $1-6$ & 20 & (23) & 12 & (15) & $1.33(0.50,3.52)$ \\
\hline$>6$ & 36 & (41) & 55 & (68) & $3.35(1.54,7.29)$ \\
\hline \multicolumn{6}{|l|}{ Mobility: } \\
\hline Walk easily & 45 & $(52)$ & 28 & (35) & 1.00 \\
\hline Walk with difficulty & 25 & (29) & 21 & (26) & $1.35(0.63,2.89)$ \\
\hline House-bound & 16 & (18) & 28 & (35) & $2 \cdot 81(1.28,6 \cdot 20)$ \\
\hline
\end{tabular}

- Housing - including tenure, central heating, and housing satisfaction;

- Social contact - including frequency of contact with friends and relatives and whether or not they lived alone.

Social class was determined from the OPCS Classification of Occupations. ${ }^{8}$
Details of the leg ulceration were collected by the nurses, including ulcer site, duration, and area of ulceration. Time to complete ulcer healing was assessed after 12 weeks of follow up.

\section{STATISTICAL ANALYSIS}

Complete healing within 12 weeks was taken as the end point for this study. For purposes of analysis, patients with bilateral ulceration were considered not to have healed if they still had an area of ulceration on either limb. Analysis was performed using logistic regression. Those factors which were associated with delayed healing were represented as odds ratios (OR) greater than unity, while factors which improved healing had odds ratios of less than one.

Age was divided into four categories, $<60$ years, 60-69 years, $70-79$ years, and $80+$

Table 2 Logistic regression analysis of factors considered to be important in the poor ulcer healing. Results are presented as odds ratios (OR) and $95 \%$ confidence intervals (95\% CI) for univariate models and following adjustment for mobility, ulcer size, and ulcer duration.

\begin{tabular}{|c|c|c|c|c|c|c|}
\hline & $\begin{array}{l}\text { Healed } \\
(n=87) \\
\text { No }\end{array}$ & & $\begin{array}{l}\text { Unh } \\
(n= \\
\text { No }\end{array}$ & $\begin{array}{l}\text { led } \\
(\%)\end{array}$ & $\begin{array}{l}\text { Unadjusted } \\
\text { OR (95\% CI) }\end{array}$ & $\begin{array}{l}\text { Adjusted } \\
\text { OR }(95 \% \text { CI })\end{array}$ \\
\hline \multicolumn{7}{|l|}{ Sex: } \\
\hline Male & 29 & (33) & 33 & (41) & & 1.00 \\
\hline Female & 58 & (67) & 48 & (59) & $0.73(0.38,1.38)$ & $0.64(0.31,1.33)$ \\
\hline \multicolumn{7}{|l|}{ Age $(y)$ : } \\
\hline$<60$ & 15 & (17) & 11 & (13) & 1.00 & 1.00 \\
\hline $60-69$ & 20 & (23) & 12 & (15) & $0.82(0.28,2.41)$ & $0.57(0.17,1.88)$ \\
\hline $70-79$ & 29 & (33) & 30 & (37) & $1.41(0.55,3.64)$ & $1.17(0.41,3.30)$ \\
\hline$\geq 80$ & 23 & (27) & 28 & (35) & $1.66(0.63,4.39)$ & $0.99(0.32,3.06)$ \\
\hline \multicolumn{7}{|l|}{ Marital status: } \\
\hline Married & 29 & (33) & 16 & $(20)$ & 1.00 & 1.00 \\
\hline Single & 17 & (20) & 26 & (32) & $2 \cdot 77(1 \cdot 15,6 \cdot 69)$ & $2.29(0.86,6.08)$ \\
\hline Widowed & 34 & (39) & 34 & $(42)$ & $1.81(0.82,3.99)$ & $1.26(0.52,3.08)$ \\
\hline Divorced/sep & 7 & (8) & 5 & (6) & $1.29(0.34,4.88)$ & $1.52(0.36,6.39)$ \\
\hline \multicolumn{7}{|l|}{ Social class: } \\
\hline I \& II & 18 & (21) & 6 & (7) & 1.00 & 1.00 \\
\hline III & 42 & (48) & 43 & (54) & $3.07(1.09,8.67)$ & $2.63(0.83,8.30)$ \\
\hline IV \& V & 27 & (31) & 31 & (39) & $3.44(1.17,10.14)$ & $2.67(0.81,8.85)$ \\
\hline \multicolumn{7}{|l|}{ Employment status: } \\
\hline Retired & 67 & (77) & 66 & $(81)$ & 1.00 & 1.00 \\
\hline Employed & 11 & (13) & 6 & (7) & $0.55(0.19,1.62)$ & $0.89(0.26,3.02)$ \\
\hline Unemployed & 1 & (1) & 4 & (5) & $4.06(0.42,39.02)$ & $4.27(0.37,49.33)$ \\
\hline Unemployed due to illness & 7 & (8) & 3 & (4) & $0.44(0 \cdot 10,1.81)$ & $0.65(0.15,2.91)$ \\
\hline Other & 1 & (1) & 2 & (2) & $2 \cdot 03(0 \cdot 17,24 \cdot 10)$ & $3.44(0.24,48.52)$ \\
\hline \multicolumn{7}{|l|}{ Income: } \\
\hline State pension + private pension & 36 & (41) & 35 & (43) & 1.00 & $1 \cdot 00$ \\
\hline State pension & 30 & (34) & 36 & (44) & $1.23(0.62,2.45)$ & $0.89(0.40,1.96)$ \\
\hline Work & 10 & (11) & 5 & (6) & $0.51(0.16,1.70)$ & $0.48(0.12,1.99)$ \\
\hline State + private pension & 8 & (9) & 4 & (5) & $0.51(0.14,1.91)$ & $0.68(0.17,2.76)$ \\
\hline Other & 3 & (3) & 1 & (1) & $0.34(0.03,3.63)$ & $0.30(0.03,3.33)$ \\
\hline \multicolumn{7}{|l|}{$\begin{array}{l}\text { Social security benefits: } \\
\text { Housing benefit }\end{array}$} \\
\hline & & $(51)$ & 40 & $(50)$ & $1 \cdot 00$ & 1.00 \\
\hline $\begin{array}{l}\text { No } \\
\text { Yes }\end{array}$ & $\begin{array}{l}44 \\
43\end{array}$ & (49) & 40 & (50) & $1.02(0.55,1.90)$ & $0.81(0.40,1.65)$ \\
\hline Mobility benefit & & & & & & \\
\hline No & 84 & (97) & 76 & (94) & 1.00 & 1.00 \\
\hline Yes & 3 & (3) & 5 & (6) & $1.84(0.41,8.21)$ & $0.99(0.17,5.94)$ \\
\hline \multicolumn{7}{|l|}{ Housing: } \\
\hline \multicolumn{7}{|l|}{ Tenure } \\
\hline Owner & 19 & (22) & 19 & (23) & $1 \cdot 00$ & $1 \cdot 00$ \\
\hline Council tenant & 42 & (49) & 25 & (31) & $0.60(0.26,1.36)$ & $0.42(0.16,1.09)$ \\
\hline Private tenant & 14 & (16) & 22 & (27) & $1.57(0.61,4.03)$ & $0.94(0.32,2.79)$ \\
\hline \multirow{2}{*}{\multicolumn{7}{|c|}{ Satisfaction with housing }} \\
\hline & & & & & & \\
\hline Yes & 75 & (87) & 66 & (81) & $1 \cdot 00$ & 1.00 \\
\hline No & 11 & (13) & 15 & (19) & $1.55(0.65,3.67)$ & $1 \cdot 14(0.42,3 \cdot 12)$ \\
\hline \multicolumn{7}{|l|}{ Central heating } \\
\hline Yes & 52 & $(60)$ & 33 & (41) & $1 \cdot 00$ & $1 \cdot 00$ \\
\hline No & 34 & (40) & 48 & (59) & $2 \cdot 22(1 \cdot 18,4 \cdot 18)$ & $2 \cdot 27(1 \cdot 11,4 \cdot 55)$ \\
\hline \multirow{2}{*}{\multicolumn{7}{|c|}{$\begin{array}{l}\text { Social isolation: } \\
\text { House occupation }\end{array}$}} \\
\hline & & & & & & \\
\hline With someone & 46 & (53) & 38 & (47) & 1.00 & 1.00 \\
\hline Alone & 40 & (47) & 43 & (53) & $1.30(0.70,2 \cdot 42)$ & $1 \cdot 21(0 \cdot 60,2 \cdot 44)$ \\
\hline \multicolumn{6}{|l|}{ Contact with family and friends } & \\
\hline Each day & 72 & (84) & 58 & (72) & 1.00 & 1.00 \\
\hline Each week & 12 & (14) & 16 & (20) & $1.66(0.71,3.84)$ & $1 \cdot 84(0 \cdot 78,4 \cdot 68)$ \\
\hline Less often & 2 & (2) & 7 & (9) & $4 \cdot 34(0 \cdot 84,22 \cdot 44)$ & $5.33(0.91,31.09)$ \\
\hline \multicolumn{7}{|l|}{ Ulcer details: } \\
\hline \multicolumn{7}{|l|}{ Limbs affected } \\
\hline One & 75 & (86) & 63 & (78) & 1.00 & 1.00 \\
\hline Two & 12 & (14) & 18 & (22) & $1.79(0.79,4.05)$ & $1.06(0.41,2.74)$ \\
\hline
\end{tabular}


Table 3 Association between recognised risk factors for prolonged healing and factors found to be important on univariate analysis

\begin{tabular}{|c|c|c|c|}
\hline & $\begin{array}{l}\text { Ulcer size } \\
>10 \mathrm{~cm}^{2}\end{array}$ & $\begin{array}{l}\text { Duration of ulcer } \\
>6 \text { mth }\end{array}$ & $\begin{array}{l}\text { Mobility } \\
\text { (housebound) }\end{array}$ \\
\hline \multicolumn{4}{|l|}{ Social class: } \\
\hline I \& II & 1.00 & 1.00 & $1 \cdot 00$ \\
\hline III & $1.27(0.32,5.00)$ & $1.09(0.43,2.80)$ & $2.03(0.61,6.74)$ \\
\hline IV \& V & $1.82(0.45,7.14)$ & $1.61(0.60,4 \cdot 36)$ & $1.87(0.54,6.55)$ \\
\hline \multicolumn{4}{|l|}{ Marital status: } \\
\hline Married & $1 \cdot 00$ & 1.00 & $1 \cdot 00$ \\
\hline Single & $3 \cdot 70(0.90,14 \cdot 28)$ & $2 \cdot 11(0.88,5.04)$ & $0.88(0.32,2.41)$ \\
\hline Widowed & $4.00(1.04,14.28)$ & $1.46(0.67,3.18)$ & $1.59(0.67,3.80)$ \\
\hline Divorced/separated & $1.28(0.11,14.28)$ & $1.25(0.34,4.59)$ & - \\
\hline \multicolumn{4}{|l|}{ Central heating: } \\
\hline Yes & 1.00 & 1.00 & 1.00 \\
\hline No & $2 \cdot 11(0.89,4.98)$ & $1.49(0.79,2.78)$ & $1.58(0.78,3.22)$ \\
\hline \multicolumn{4}{|l|}{ Contact: } \\
\hline Every day & 1.00 & 1.00 & 1.00 \\
\hline Every week & $0.56(0.15,2.04)$ & $0.79(0.34,1.85)$ & $1.07(0.42,2.71)$ \\
\hline Less often & $1.33(0 \cdot 25,7 \cdot 14)$ & $1.71(0.40,7 \cdot 35)$ & $0.76(0.15,3.99)$ \\
\hline \multicolumn{4}{|l|}{ Ulcer site: } \\
\hline Unilateral & 1.00 & 1.00 & 1.00 \\
\hline Bilateral & $4 \cdot 12(1 \cdot 65,10 \cdot 32)$ & $2.38(1.00,5.56)$ & $2 \cdot 27(0.95,5 \cdot 26)$ \\
\hline
\end{tabular}

years. Ulcer duration was categorised into $<1$ month, 1-6 months, and $>6$ months, in line with previously published results. ${ }^{6} \mathrm{OR}$ and $95 \%$ CI were calculated from the coefficients and standard errors of the variables when fitted into the logistic regression model. The factors examined were also adjusted for recognised risk factors of poor healing. Finally, the socioeconomic factors which seemed to be important on univariate analysis were examined to show their relationship with the known risk factors.

\section{Results}

In all, 168 patients presented with leg ulceration and were suitable for 4LB. Patients had a mean (SD) age of 76 (11) years, and 106 $(64 \%)$ were women. Most patients $(82 \%)$ had unilateral ulceration. Altogether 140 of 168 $(82 \%)$ had an area of ulceration less than $10 \mathrm{~cm}^{2}$ with a median duration of ulceration of 7 months (range 1 week to 63 years). Most patients $(79 \%)$ were retired, with the combination of social security and private pension being the most frequent source of income $(42 \%)$. Half the patients received housing benefit, while $40 \%$ were council tenants and only $22 \%$ were owner occupiers. Of the total, half had central heating and only $15 \%$ expressed dissatisfaction with their housing conditions. One half of patients lived alone. Despite this, over three quarters of all patients saw family or friends every day.

Mobility was generally poor in this elderly group. Altogether 44 of 163 (27\%) described themselves as housebound, and a further 46 of $163(28 \%)$ only walked outside with difficulty.

The univariate analysis of recognised risk factors for prolonged healing are given in table 1. As expected, even in this relatively small sample, large ulcer size, long duration of ulceration, and poor general mobility were all significantly associated with prolonged healing. Analysis of the socieconomic factors studied (table 2) showed a number of significant associations with poor healing over the 12 weeks of treatment. Being single seemed to prolong healing ( $O R=2 \cdot 77)$, and there was a clear gradient of healing in relation to social class.
Those patients in social classes IV and V had a more than threefold chance of having unhealed ulcers compared with patients from social classes I and II.

Housing factors seemed to be important. Lack of central heating was related to poor ulcer healing $(\mathrm{OR}=2 \cdot 22,95 \% \mathrm{CI} 1 \cdot 18,4 \cdot 18)$. There were high ORs for both housing satisfaction ( $O R=1.55)$ and solitary occupation $(\mathrm{OR}=1 \cdot 30)$, but neither achieved statistical significance. Frequency of contact with relatives and friends also showed an important trend. Those patients who said they had social contact less than once per week were four times more likely to have ulcers that remained unhealed after 12 weeks than patients who had regular daily contact with others.

When adjusting these factors for the known risk factors of ulcer size, duration, and mobility, the OR reduced, to the extent that only lack of central heating remained statistically significant $(\mathrm{OR}=2 \cdot 27,95 \% \mathrm{CI} 1 \cdot 11,4 \cdot 55)$. To try to understand this change, an analysis was performed comparing the social factors found to be important on univariate analysis with the recognised risk factors (table 3 ). There were high ORs $(>2)$ for large ulcer size and single patients, widows, lack of central heating, and bilateral ulceration, while long duration of ulceration was associated with single patients and bilateral ulceration. Being housebound was associated with social class III, and bilateral ulceration.

\section{Discussion}

In 1799, Charles Brown, a surgeon, wrote in the Medical and Physical fournal of the problem of leg ulceration: "It is a melancholy fact that among the lower classes of the community, nearly in the proportion of one out of five, labour, and have for many years, under this severe affliction". ${ }^{9}$ Since that time leg ulceration has been considered a problem of the socially deprived, but with little evidence to support this. Despite extensive clinical studies, little is known of the potential effects of socioeconomic factors on ulcer healing. The Tubingen study found that venous disease, including ulceration, was more common in lower social classes. ${ }^{10}$ This as not confirmed in the Lothian and Forth Valley study, however, which concentrated on leg ulceration only, and identified a social class distribution that was similar to the resident population. ${ }^{11}$ Their data showed, however, that longer duration of ulceration was associated with lower social class. This finding is confirmed by our study which showed improved healing in higher social classes.

It has long been recognised that clinical factors may influence leg ulcer healing. A recent evaluation of patients originally entered into a clinical trial identified large ulcer area, long duration, old age, and deep vein disease as important factors in delaying healing of ulcers. ${ }^{12}$ Other studies have either failed to find significant predictors of poor healing, or have simply confirmed the importance of ulcer size or duration. ${ }^{13-15}$ From the clinical data provided in the Riverside project, poor general mobility 
was identified as an independent risk factor for poor healing together with large ulcer size and long duration. ${ }^{16} \mathrm{~A}$ recent study from Australia found a similar distribution of mobility to that reported here, though there was no attempt to relate this to outcome measures. ${ }^{17}$

One surprising finding was the importance of central heating in the healing of ulcers. This may be important in two ways. Firstly, the association may be a reflection of economic status which the other economic variables such as income and housing tenure have failed to detect. Secondly, however, the lack of central heating may cause a physiological response in patients with leg ulceration. Patients are warned routinely not to toast their legs in front of fire. It is suspected that toasting may lead to changes in the wound bed, leading to delayed healing of the ulcerated area (Coleridge Smith P, 1994, personal communication). At present it is not possible to determine which of these factors is the more important.

The present study gives information from a health district wide service that provides leg ulcer care using "state of the art" techniques in assessment and treatment within a community care initiative. We have investigated socioeconomic factors that might influence leg ulcer healing in patients with venous ulceration treated by a standard regimen. Although we found associations between socioeconomic factors and poor healing, adjustment for known risk factors led to a generalised reduction in the OR leading to non-significant associations. Of the factors which were statistically significant on univariate analysis, only lack of central heating remained significant after adjustment. Clearly further work is needed on larger samples of patients to determine whether the high OR found here are chance associations or whether they have a causative effect on the healing of chronic venous ulceration. This work was part funded by the King Edward's Hospital
Fund for London. We thank members of Riverside Community Fealthcare Trust for their support in this work.

1 Callam MJ, Ruckley CV, Harper DR, Dale JJ. Chronic ulceration of the leg: extent of the problem and provision of care. BMf 1985; i:1855-6.

2 Cornwall JV, Dore CJ, Lewis JD. Leg ulcers: epidemiolog and aetiology. Br f Surg 1986;73:693-6.

3 Dale JJ, Callum MJ, Ruckley CV, Harper DR, Berrey PN. Chronic ulcers of the leg: a study of prevalence in Scottish community. Health Bull 1983;41:310-4.

4 Bosanquet N, Franks PJ, Moffatt CJ, et al. Community leg ulcer clinics: cost effectiveness and future development. Health Trends 1993;25:146-8.

5 Blair SD, Wright DDI, Backhouse CM, Riddle E, McCollum $C N$. Sustained compression and healing of chronic venous ulcers. $B M F$ 1988;297:1159-61.

6 Moffatt CJ, Franks PJ, Oldroyd M, Bosanquet N, Brown $\mathrm{P}$, Greenhalgh RM, McCollum CN. Community leg ulce clinics and impact on healing. BMF 1992;305:1389-2.

7 Franks PJ, Wright DDI, Moffatt CJ, Stirling J, Fletcher AE Bulpitt CJ, McCollum CN. Questionnaire for risk factors in venous disease. Eur $\mathcal{F}$ Surg 1992;158:149-55.

8 Office of Population Censuses and Surveys. Standard occupational classification. Vols 1-3. HMSO, London 1991.

Loudon ISL: Leg ulcers in the eighteenth and early nineteenth centuries. F Roy Coll Gen Pract 1981;31:263-73.

10 Fischer H. Venenleiden-Eine representative Untersuchung in der Bundesrepublik Deutschland. Munich: Urban and Schwarzenberg, 1981.

11 Callam MJ, Harper DR, Dale JJ, Ruckley CV. Chronic leg ulceration: socioeconomic aspects. Scot Med $\mathcal{F} 1988 ; 33$ : 358-60.

12 Skene AI, Smith JM, Dore CJ, Charlett A, Lewis JD. Venous leg ulcers: a prognostic index to predict time to healing.

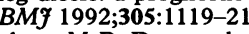

13 Colgan M-P, Dormandy JA, Jones PW, Schraibman IG Shanik DG, Young RAL: Oxpentifylline treatment of venous ulcers of the leg. $B M F$ 1990;300:972-4.

14 Stewart AJ, Leaper DJ. Treatment of chronic leg ulcers in the community: a comparative trial of Scherisorb and iodosorb. Phlebology 1987;2:115-21.

15 Kikta MJ, Schuler JJ, Meyer JP, et al. A prospective, randomized trial of Unna's boots versus hydroactive dressing in the treatment of venous stasis ulcers. $\mathcal{F}$ Vasc Surg 1988 ; 7:478-83.

16 Franks PJ, Moffatt CJ, Oldroyd M, Bosanquet N, Connolly M, Greenhalgh RM, McCollum CN: Factors associated with healing venous ulcers. Age and Ageing 1995; (In press.)

17 Baker SR, Stacey MC, Jopp-McKay AG, Hoskin SE Thompson PJ. Epidemiology of chronic venous ulcers. $B$ f Surg 1991;78:864-7. 